\title{
Naturverhältnisse in der Krise: Gesellschaftliches Handeln und natürliche Prozessualität in der Covid-19-Pandemie
}

\author{
Relations to Nature in Crisis: Societal Action and Natural \\ Processes in the COVID-19 Pandemic
}

\section{Jonas Heller, Frankfurt am Main}

Zusammenfassung: In der gegenwärtigen Corona-Krise erscheinen die Entstehung der Krise - die Verbreitung der Krankheit Covid-19 zur Pandemie - und die Bewältigung der Krise - die rechtlichen Einschränkungen und Maßnahmen - scharf getrennt. Die Entstehung der Krise geht auf ein Stück Natur zurück, auf ein für Menschen bedrohliches Virus. Die Bewältigung der Krise geht mit staatlichem und gesellschaftlichem Handeln einher, das in zahlreichen Ländern im Rahmen rechtlicher Ausnahmezustände erfolgte. Den markanten Trennungspunkt zwischen Entstehung und Bewältigung der Krise bildet die Ausrufung der Ausnahmemaßnahmen, durch die in das Pandemiegeschehen interveniert wurde. Diese Einteilung kann den Eindruck erwecken, die mit Natur verbundene Entstehung der Krise sei eine Zeit, die gänzlich vor dem Handeln liegt: eben die Zeit des natürlichen Prozesses, die von der mit Handeln verbundenen Bewältigung der Krise abgekoppelt sei. Dieser Aufsatz zielt demgegenüber darauf, die Phasen der Entstehung und der Bewältigung der Corona-Krise in ihrer jeweiligen Ambivalenz hervortreten zu lassen. Das Ziel ist dabei ein doppeltes: Einerseits soll hervortreten, inwiefern die Phase der Entstehung der Krise nicht nur prä-aktiv und die Krise damit keine bloß natürlich gegebene, sondern auch eine gesellschaftlich gemachte ist. Andererseits soll deutlich werden, in welcher Weise die Phase der Bewältigung der Pandemie nicht allein krisenreaktiv, sondern auch krisenproduktiv ist.

Einleitend werde ich die genannte Zeitlichkeit - Entstehung und Bewältigung - erläutern, die einem gängigen Krisenverständnis zugrunde liegt, das auch in der gegenwärtigen Pandemie wirksam ist. Darauf werde ich darlegen, inwiefern das Denken des Ausnahmezustands ein Denken ebendieser Zeitlichkeit und damit zweier Phasen der Krise ist (I.1), und zeigen, warum sich die gegenwärtige Krise gerade aufgrund ihrer Verbindung mit Natur in dieses Denken einfügt (I.2). Auf dieser Grundlage gehe 
ich dazu über, ein komplizierteres Verständnis der gegenwärtigen Krise zu gewinnen, indem ich darlege, wie in ihrer Entstehung natürliche Prozessualität und gesellschaftliches Handeln untrennbar zusammenwirken (II.1) und an welchen Punkten ihrer Bewältigung die Krisenreaktion so in Krisenproduktion umschlägt, dass das gesellschaftliche bzw. staatliche Handeln wiederum auf Natur zurückwirkt (II.2). Durch diese Schritte soll deutlich werden, inwiefern sich in der gegenwärtigen Krise weder natürliche Prozesse und soziale Praxis noch Krisenreaktion und Krisenproduktion äußerlich gegenüberstehen, sondern intern verbunden sind. Das eingangs erläuterte Krisenverständnis erfährt dadurch eine Modifikation.

Schlagwörter: Natur, Maßnahme, Krise, Recht, Ausnahmezustand

Abstract: In the current corona crisis, the emergence of the crisis - the spread of the COVID-19 disease to a pandemic - and the coping with the crisis - the legal restrictions and measures - appear to be sharply separated. The emergence of the crisis goes back to a piece of nature, to a virus threatening for humans. The coping with the crisis is carried out through governmental and societal action, which in many countries took place within the framework of legal states of exception. The pronounced dividing line between the emergence and the coping with the crisis is the proclamation of the exceptional measures that intervened in the pandemic. This division can give the impression that the emergence of the crisis is a time that lies entirely before action: a time of natural process, separated from the crisis management which is associated with action. In contrast, this article aims to show the phases of the emergence and management of the corona crisis in their respective ambivalence. The aim is twofold: On the one hand, it is to be shown to what extent the phase of the emergence of the crisis is not only pre-active and the crisis is therefore not just a natural one, but also socially made. On the other hand, it should become clear in what way the phase of coping with the pandemic is not only crisis-reactive, but also crisis-productive.

I will begin by explaining the temporality - emergence and coping - that characterizes a common understanding of crisis, which is also effective in the current pandemic. I will then explain to what extent the thinking of the state of exception is a thinking of this very temporality and thus of two phases of crisis (I.1), and show why the present crisis fits into this thinking precisely because of its connection with nature (I.2). On this basis, I proceed to develop a more complex understanding of the current crisis by explaining how natural processes and societal action work inseparably together (II.1), and at which points in the process of coping, the crisis reaction turns into crisis production in such a way that societal or governmental action in turn affects nature (II.2). These steps are intended to make clear to what extent in the current crisis neither natural processes and social practice nor crisis reaction and crisis production are externally opposed to each other, but are internally connected. The understanding of crisis explained at the beginning is thereby modified.

Keywords: nature, measure, crisis, law, state of exception 


\section{Einleitung: Die Temporalität der Krise}

Am 11. März 2020 erklärte die Weltgesundheitsorganisation (WHO) die Krankheit Covid-19 zur Pandemie. ${ }^{1}$ Ein halbes Jahr später, am 23. September 2020, zog der Virologe Christian Drosten gegenüber der Frankfurter Allgemeinen Zeitung Bilanz über den Zusammenhang zwischen der Ausbreitung der Krankheit in Deutschland und den weithin als erfolgreich eingeschätzten staatlichen Maßnahmen. Die nationale Leistung relativierend sagte Drosten: „Wir haben mit genau den gleichen Mitteln reagiert wie andere. Wir haben nichts besonders gut gemacht. Wir haben es nur früher gemacht" (Drosten 2020a). Die entscheidende Differenz zu anderen Ländern liegt demnach weniger darin, wie gehandelt wurde (besonders gut), sondern wann gehandelt wurde (besonders früh). Dass zeitig reagiert wurde, erklärt die Griffigkeit der Maßnahmen und die über den Sommer gemäßigte Ausbreitung von Covid-19 in Deutschland. Mit dieser Einschätzung trifft sich, dass umgekehrt in anderen Ländern schon im Frühjahr kritisiert wurde, den richtigen, d.h. frühen Handlungszeitpunkt verpasst zu haben. So wurde etwa Boris Johnson Mitte April durch seinen ehemaligen „chief scientific adviser“ David King öffentlich vorgeworfen, auf den gegebenen Notfall zu spät mit den notwendigen Maßnahmen reagiert zu haben (vgl. Mason 2020).

Die Einschätzungen von Christian Drosten und David King machen zwei Aspekte sichtbar, die einem gängigen Verständnis nach zu einer Krise gehören: Der eine Aspekt ist eine diagnostizierte Krisenlage - hier die Verbreitung der Krankheit Covid-19 zur gesundheitlichen Pandemie -, der andere Aspekt ist eine therapeutische Krisenintervention - hier die von den Regierungen beschlossenen rechtlichen Einschränkungen und politischen Maßnahmen. Die beiden Aspekte der Krise stehen in einer zeitlichen Abfolge, so dass sich in einer Krise, wird sie nicht einfach resignativ hingenommen, zwei Szenarien verbinden: retrospektiv ein Szenario der Entstehung, prospektiv ein Szenario der Bewältigung. Diese zeitliche Struktur bringt Drosten im Hinblick auf die Corona-Krise zum Ausdruck: Die entstandene Krise wurde als solche - als bedrohliche Lage, die eine dringende Reaktion erfordert - in Deutschland früher als andernorts ernst genommen und die bewältigenden Maßnahmen wurden zeitig eingesetzt. Eine solche Temporalität der Krise - die Abfolge von Entstehung und Bewältigung - entspricht

$1 \quad$ Siehe den Text der Erklärung: https://www.who.int/dg/speeches/detail/ who-director-general-s-opening-remarks-at-the-media-briefing-on-covid19---11-march-2020 (abgerufen am 8.10.2020). 
einem klassischen Krisenverständnis, wie es sich etwa bei dem von Carl Schmitt beeinflussten Historiker Reinhart Koselleck findet. In seinem Buch Kritik und Krise schreibt Koselleck: „Es liegt im Wesen einer Krise, daß eine Entscheidung fällig ist, aber noch nicht gefallen“ (Koselleck 1973, 105). Den Punkt einer fälligen Entscheidung nicht oder weniger verpasst und in die Krise zeitnah interveniert zu haben, ist das, was Drosten schon im Frühjahr als „Vorsprung“ bezeichnet und davor gewarnt hat, ihn zu verspielen (vgl. Drosten 2020b und 2020c). Im Vorsprung sah Drosten eine „von der Natur“ gegebene Chance, denn die Ausbreitung der Krankheit sei eine „Naturkatastrophe, die in Zeitlupe abläuft“ (Drosten 2020c, 2). Das Naturgeschehen der Krankheitsverbreitung gelte es, so Drosten am 11. März im Interview, durch „gezielte und gute Maßnahmen“ einzudämmen (ebd.). Der bei Koselleck genannten Zeit vor der Entscheidung entspricht in dieser Aussage Drostens die Phase vor der Intervention in den Naturverlauf der Ausbreitung.

Die hier anklingende Gegenüberstellung einer mit Natur verbundenen Krisenentstehung einerseits und einer durch Maßnahmen betriebenen Krisenbewältigung andererseits legt einen scharfen Gegensatz von Handeln und Nichthandeln nahe: Als ein an Natur geknüpftes Geschehen liegt die Krisenentstehung vor dem Handeln, sie ist prä-aktiv; dagegen bezieht sich die Krisenbewältigung handelnd auf die nunmehr gegebene Krise, sie ist re-aktiv. Diese Sichtweise ist richtig, insoweit sie sich allein auf das Kriterium der Intervention, d.h. der politisch beschlossenen und umgesetzten Maßnahmen bezieht. Drosten hat also recht, wenn er sagt, dass dieses Handeln - die Intervention durch Krisenmaßnahmen - in verschiedenen Ländern zu unterschiedlichen Zeitpunkten eingesetzt hat; und es leuchtet ebenfalls ein, dass der Zeitpunkt dieses Handelns den jeweiligen Verlauf der Ausbreitung von Covid-19 in unterschiedlichen Ländern mitbestimmt hat. Allerdings lässt sich die Corona-Krise (und das war auch nicht Drostens Intention) nicht begreifen, wenn sie allein durch diesen Zusammenhang von Krise und Handeln beschrieben wird: einen Zusammenhang, dessen eine Seite - die Krisenlage - sich jenseits von Handeln ergibt und dessen andere Seite - die Intervention durch Maßnahmen - allein als Lösung der Krise in Betracht kommt. Demgegenüber verfolgt dieser Aufsatz ein doppeltes Ziel. Einerseits soll deutlich werden, inwiefern die Phase der Entstehung der Krise (die Verbreitung von Covid-19 zur Pandemie) nicht nur prä-aktiv und die Krise damit keine bloß „natürlich“ gegebene, sondern auch eine gemachte ist. In Frage steht hier, welche Rolle ein gesellschaftliches Handeln auch diesseits (also vor) der Krisenintervention spielt; denn das Handeln der In- 
tervention ist nicht das einzig für die Krise relevante. Welches Handeln also trägt, vor den staatlichen Maßnahmen, zur Entstehung der Krise bei, indem es sich mit der Naturprozessualität des Virus verbindet? Andererseits soll deutlich werden, in welcher Weise die Phase der Bewältigung der Pandemie (die rechtlichen Ausnahmemaßnahmen) nicht allein krisenreaktiv, sondern auch krisenproduktiv ist. In Frage steht hier, inwiefern die durch staatliches Maßnahmehandeln stattfindende Intervention nicht nur die Krise lösende, sondern auch sie auslösende Effekte hat. Gegenüber der Temporalität der als klassisch akzentuierten Sicht auf die Krise bedeutet diese doppelte Fragerichtung eine Irritation, insofern die Entstehung der Krise nicht jenseits von Handeln und die Bewältigung der Krise nicht allein als deren Lösung in den Blick kommt.

Der Aufsatz entfaltet dieses Argument in zwei Schritten. Im ersten Teil (I) soll der Trennungspunkt genauer in Betracht kommen, anhand dessen dem klassischen Krisenverständnis zufolge die Entstehung und die Bewältigung der Krise in zwei Phasen unterschieden und beide aufeinander bezogen werden. Dieser Trennungspunkt liegt, wie angedeutet, in der Intervention, durch die auf eine Krise reagiert wird. Er lässt sich in der gegenwärtigen Corona-Krise deshalb klar fassen, weil er durch die vielerorts erklärten Ausnahmezustände und die auf dieser Grundlage ergriffenen Maßnahmen markiert ist. Inwiefern die Logik des Ausnahmezustands generell einem Zwei-Phasen-Denken der Krise entspricht, werde ich im ersten Abschnitt (I.1) erläutern. Zugleich soll deutlich werden, dass jeder Ausnahmezustand auf der Ebene des Rechts eine Krisensituation hervorbringt, die zuvor nicht bestand: Auf eine als faktisch festgestellte Krise wird im Ausnahmezustand dadurch reagiert, dass eine rechtliche Krise produziert wird. Diese rechtliche Krise, die der Ausnahmezustand bewirkt, macht ihn zum Gegenstand der Kritik. Je evidenter allerdings die faktisch festgestellte Krise erscheint, die dem Ausnahmezustand vorausgeht, desto legitimer und damit kritikfester erscheint dieser. Im zweiten Abschnitt (I.2) werde ich darlegen, inwiefern die gegenwärtige Corona-Pandemie dieses Kriterium einer faktischen Krisenlage erfüllt und damit begünstigt, dass die Ausnahmemaßnahmen weithin als legitim akzeptiert werden. Einen Grund dafür sehe ich darin, dass die gegenwärtige Krise in einem engen Verhältnis mit Natur (mit der Natur des Virus) steht und natürliche Prozesse als vom Handeln getrennt erscheinen: Sie entstehen zunächst und auf sie wird - in einer zweiten Phase - reagiert. Gerade im Naturaspekt der Krise wird daher ihr „Realitätsgehalt“, d.h. ihr wirkliches und vor den Maßnahmen gegebenes Vorliegen gesehen. Der zwei- 
te Teil (II) fragt demgegenüber nach einem differenzierteren, weniger homogenen Verständnis der Phase vor und der Phase nach der Intervention durch Maßnahmen. Im dritten Abschnitt (II.1) steht im Fokus, in welcher Weise sich in der Entstehung der Krise, d.h. vor der Intervention, die natürlichen Prozesse mit gesellschaftlichem Handeln untrennbar verbinden. Gefragt wird hier, inwiefern die Beschreibung der Pandemie als „Naturkatastrophe“ den Zusammenhang von natürlicher Prozessualität und gesellschaftlicher Praxis unzureichend beschreibt. Der vierte Abschnitt (II.2) gilt der Frage nach der Krisenproduktivität der Corona-Maßnahmen: In welcher Weise bringen die im Rahmen von Ausnahmezuständen erfolgenden Interventionen die Krisenlage mit hervor und welche Folgen hat das Maßnahmehandeln für die auch natürliche Existenz von Menschen? Auf die Verbindung von Naturprozessualität und gesellschaftlichem Handeln soll im Schlussabschnitt im Hinblick auf die Entstehung und Bewältigung der Krise zusammenfassend reflektiert werden, denn weder ist die Krise in ihren unterschiedlichen Aspekten schlicht als Katastrophe der Natur noch einfach als Maßnahme von Menschen zu begreifen.

\section{Krisenlage und Krisenmaßnahme}

\section{I.1 Ausnahmezustand: Das Verhältnis von gegebener Krise und reaktivem Handeln}

Reinhart Koselleck hat, wie eingangs erwähnt, die Krise als eine Lage bestimmt, in der eine Entscheidung fällig ist. Das Fallen einer solchen Entscheidung markiert einen zeitlichen Einschnitt: Rückblickend macht die Entscheidung geltend, dass sich ein Zustand der Krise ergeben hat, vorausblickend leitet sie die Maßnahmen ein, die diesen Zustand praktisch beheben sollen. Ein solcher Einschnitt, der - wie Drosten bemerkt hat - früher oder später erfolgen kann, ist auch in der gegenwärtigen Corona-Krise festzustellen. Er wird besonders darin manifest, dass auf die gesundheitliche Pandemie in zahlreichen Ländern durch die Deklaration rechtlicher Ausnahmezustände reagiert wurde. Ein Ausnahmezustand besteht nur, wenn er explizit erklärt wird; er ist stets Folge einer Entscheidung. Im Rahmen der Pandemie im Jahr 2020 hatten bis Mitte April 98 Regierungen einen Ausnahmezustand erklärt (vgl. Bjørnskov und Voigt 2020). ${ }^{2}$ Dies ermöglichte rechtliche

2 Zur Frage, inwiefern hinsichtlich der Bundesrepublik Deutschland von einem rechtlichen Ausnahmezustand gesprochen werden kann, vgl. unten, S. $486 f$. 
Maßnahmen (Einschränkung von Grundrechten), um der gesundheitlichen Krisenlage (Verbreitung der Krankheit Covid-19) entgegenzutreten. Das Verhältnis von rechtlichen Einschränkungen und gesundheitlicher Lage war dabei von Beginn an Gegenstand der Kritik. Von verschwörungsmythischen Kreisen einmal abgesehen, auf die ich am Ende des Aufsatzes zu sprechen komme, setzte diese Kritik insbesondere an zwei Stellen an. Einerseits betraf sie den Inhalt der Maßnahmen. Fraglich war hier zunächst, ob die Maßnahmen, auch das inzwischen weithin befürwortete Tragen von Masken, im Hinblick auf die Ausbreitung der Krankheit überhaupt wirksam sind und ob die Wirkung, die durch Lockdowns erzielt werden sollte, die ökonomischen Folgen rechtfertigen kann. $\mathrm{Zu}$ einem wichtigen Teil beruhte (und beruht) diese Kritik auf dem großen Nichtwissen über das neuartige Virus: über den Weg seiner Übertragung und das Maß seiner Gefährlichkeit sowie über die Auswirkungen in Wirtschaft und Gesellschaft (vgl. Schwering 2020). Andererseits betraf die Kritik die Modalität der Einsetzung der Maßnahmen, die Weise nämlich, in der sie exekutiv beschlossen wurden. Auf diese Kritik, die von der Sorge um die Gewaltenteilung im demokratischen Rechtsstaat getragen ist, werde ich in Abschnitt II.2 eingehen. An dieser Stelle soll eine grundsätzlichere Problematik im Fokus stehen, die das Verhältnis von Krisenlage und Krisenmaßnahmen nicht allein in der konkreten gegenwärtigen Situation betrifft, sondern im rechtlichen Phänomen des Ausnahmezustands selbst gründet. Diese Problematik liegt darin, dass die rechtlichen Entscheidungen, durch die Ausnahmemaßnahmen beschlossen werden, nicht nur Mittel der Reaktion sind, durch die eine bestehende Krise bewältigt werden soll, sondern auch eine krisenproduktive Wirkung haben: Der Ausnahmezustand, der die faktische Normalität wieder herstellen soll, suspendiert zugleich die rechtliche Normalität und führt dadurch in eine Krise des Rechts. Um diese Krise, in die das Recht gerät, deutlich zu machen, muss im Folgenden zunächst das Phänomen des Ausnahmezustands erläutert werden sowie die rechtliche Logik, nach der er funktioniert und in der sich Krisenreaktion und Krisenproduktion verbinden.

Der Politikwissenschaftler Matthias Lemke versteht unter „Ausnahmezustand“ eine „Vielzahl empirisch auffindbarer Krisenreaktionsmechanismen im Rahmen ausdifferenzierter Staatlichkeit“, welche die „Handlungs- und Entscheidungsfähigkeit der Regierung“ erweitern sollen, „wenn die Umstände dies erfordern“ (Lemke 2019, 292f.). Dass eine Krise vorliegt, ist somit die Voraussetzung des Ausnahmezustands. Denn er ist ein Mittel, um auf Krisen zu reagieren: ein „Krisenreaktionsmechanismus“. Die Mecha- 
nismen, aus denen er jeweils besteht, versetzen die Regierung in die Lage, über angemessene Maßnahmen und ihre Umsetzung zu entscheiden. Verstanden als rechtlicher Mechanismus, vermittelt der Ausnahmezustand zwischen der gefährlichen Krise und den folglich fälligen Entscheidungen. Die Krise erfordert den Ausnahmezustand, weil er die Entscheidungen zu ihrer Bewältigung möglich macht. Krise - Ausnahmezustand - Entscheidung: Diese Abfolge ist für den Ausnahmezustand, seiner rechtlichen Idee nach, konstitutiv.

Doch ermöglicht der Ausnahmezustand nicht nur künftige Entscheidungen, sondern ist selbst das Ergebnis einer Entscheidung. Den exekutiven Entscheidungen im Ausnahmezustand geht die Entscheidung über den Ausnahmezustand voraus. Diese Entscheidung über den Ausnahmezustand hat bekanntlich Carl Schmitt in den Fokus gerückt. In Politische Theologie schreibt Schmitt (2009, 14): „Er [der Souverän] entscheidet sowohl darüber, ob der extreme Notfall vorliegt, als auch darüber, was geschehen soll, um ihn zu beseitigen.“ Die Entscheidung über die Maßnahmen, die die Krise bewältigen sollen, ist nach Schmitt nur die eine und nicht die maßgebende Seite souveränen Entscheidens. Wichtiger ist die Entscheidung, $o b$ eine Krise im Sinne des ,extremen Notfalls ${ }^{6}$ besteht. Ein solcher Notfall ist dem Recht nach Schmitt nicht äußerlich: Nicht bloß die außerrechtliche Lage ist in ihm aus den Fugen, sondern auch das bestehende Recht selbst. Es kann sich nicht mehr in die veränderte Lage fügen, auf die Krisensituation ist es nicht mehr anwendbar. Schmitt begründet dies damit, dass die generellen Normen des Rechts eine „normale Gestaltung der Lebensverhältnisse“ voraussetzen, auf die sie angewandt werden können (ebd., 19). Weil diese Normalität der Lebensverhältnisse im extremen Notfall nicht mehr gegeben ist, gerät auch das Recht in Not: Es wird inpraktikabel. Im Notfall steht die Praxis des Rechts selbst auf dem Spiel; dass ein Notfall besteht, heißt, dass kein Rechtsfall mehr möglich ist. Deshalb bildet ein Notfall, der durch das bestehende Recht nicht zu lösen ist, einen Notfall für das bestehende Recht.

Auf diesen Notfall, der für das Recht besteht, wird im Ausnahmezustand durch eine Krise des Rechts reagiert. Diese Krise des Rechts selbst es ist banal und gleichwohl wichtig, es sich zu vergegenwärtigen - besteht schlicht darin, dass das Recht durch die Erklärung eines Ausnahmezustands in einen Zustand versetzt wird, in dem es nicht mehr normal operiert: Die Krise des Rechts liegt in der Aufhebung seiner Normalität. In liberalen demokratischen Rechtsstaaten besteht diese Normalität in der Geltung von Grundrechten und Gewaltenteilung. Im Ausnahmezustand treten dagegen 
exekutiv erlassene Maßnahmen teilweise an die Stelle legislativ beschlossener Normen und beinhalten regelmäßig die Einschränkung oder Aufhebung von Grundrechten. Das Recht wird so - im Rahmen des Rechtsstaats - seinem rechtsstaatlichen Operieren entfremdet und nimmt eine Praxis an, die unter rechtsstaatlichen Gesichtspunkten als außerrechtlich erscheint. Darin besteht die Krise, in die das Recht mit dem Ausnahmezustand eintritt. Diese Krise ist nicht dasselbe wie der Notfall, der für das Recht besteht, sondern sie wird aufgrund dieses Notfalls eingeleitet. Die rechtlichen Verfahren, in denen das Recht normalerweise operiert, werden unterbrochen und stattdessen wird unmittelbar in die krisenhaften ,Lebensverhältnisse interveniert. Diese Intervention zielt darauf, den Notfall in der Welt und damit auch die Not des Rechts zu beseitigen, um mit der faktischen Normalität auch den rechtlichen Normalzustand wieder herstellen zu können.

Auf den außerrechtlichen Notfall, der auch das Recht in Not bringt, wird mit dem Ausnahmezustand durch eine Krise des Rechts reagiert. Dies ist eine Beschreibung nach Schmitt, nicht Schmitts eigene Beschreibung. Denn im Ausnahmezustand sieht Schmitt nicht eine Krise des Rechts, sondern die Offenbarung seiner Form, die - so sein grundlegendes Argument nicht nur in der Politischen Theologie, sondern auch in der Verfassungslehre (Schmitt 2010; dazu näher Heller 2018, 116ff.) - auch für das rechtsstaatliche Recht das bestimmende Moment bildet. Die Form des Rechts ist nach Schmitt die souveräne Entscheidung, die er als wesentlich personal (und damit letztlich nicht als demokratisch) versteht. Weil im Ausnahmezustand gerade jenes Moment souveränen Entscheidens „rein“ zur Geltung kommt, das für Schmitt auch die Normalität des Rechts bestimmt, manifestiert sich Schmitt zufolge in der Entscheidung über den Ausnahmezustand die zu akzeptierende Wahrheit des Rechts, nicht dessen Krise. Auch wenn ich hier, gegen Schmitt, den Ausnahmezustand als Krise des Rechts begreife, lässt sich anhand von Schmitt die für den Ausnahmezustand konstitutive Entscheidung detaillierter erläutern.

Die souveräne Entscheidung über den ,extremen Notfall‘ konstatiert nach Schmitt, ob ein faktisch normaler Zustand der Lebensverhältnisse, in dem auch rechtlich normal operiert werden kann, „wirklich herrscht“ (Schmitt 2009, 19). Zur souveränen Entscheidung gehört demnach zunächst eine Unterscheidung: die Unterscheidung zwischen faktischem Normalfall und faktischem Notfall bzw. das Urteil darüber, welchem dieser zwei Fälle die gegebene Situation entspricht. In diesem unterscheidenden Aspekt ist die souveräne Entscheidung bloß kognitiv: Sie stellt fest, ohne der Welt 
praktisch etwas hinzuzufügen. ${ }^{3}$ An dieses kognitive Urteil über die faktische Lage knüpft sich stets ein praktischer Entschluss über die rechtliche Lage: der Entschluss, ob rechtlich ein Normalzustand bestehen kann oder ein Ausnahmezustand eintreten muss. Die souveräne Entscheidung über den Ausnahmezustand, die permanent erfolgt, enthält diese beiden Aspekte: das kognitive Urteil und den praktischen Entschluss.

Stellt das kognitive Urteil fest, dass kein extremer Notfall vorliegt und somit der rechtliche Normalzustand weiter gelten kann, fällt die souveräne Entscheidung stumm aus: Weil entschieden wird, dass es nichts zu ändern gilt, gibt es nichts zu erklären. Eine souveräne Erklärung wird nur im Notfall fällig, in dem es nicht um ein Weiterlaufen der Rechtspraxis, sondern um deren Unterbrechung geht. Dabei erklärt die Deklaration des Ausnahmezustands beides: den faktischen Notfall (als Ergebnis des kognitiven Urteils) und den rechtlichen Ausnahmefall (als Ergebnis des praktischen Entschlusses). In der Erklärung des Ausnahmezustands hängen diese beiden Aspekte zusammen: Durch die faktische Notlage wird der Ausnahmezustand notwendig und durch diese faktische Notwendigkeit erscheint er rechtlich berechtigt. Das kognitive Urteil über den Notfall muss den praktischen Entschluss über den Ausnahmezustand begründen und ihm daher logisch vorausgehen. Nur dann erscheint ein Ausnahmezustand berechtigt, denn nur dann entspricht er seinem rechtlichen Begriff: Reaktion auf eine gegebene Krise zu sein.

Doch steht das Urteil über die faktische Lage, wie erwähnt, nicht außerhalb der souveränen Entscheidung über den Ausnahmezustand, sondern ist Teil von ihr: Im Akt der souveränen Erklärung des Ausnahmezustands fallen kognitives Urteil und praktischer Entschluss in einer Entscheidung zusammen. Anders formuliert: Es wird rechtlich entschieden, was faktisch der Fall ist. Dass über das Vorhandensein einer Krise mit der Erklärung des Ausnahmezustands rechtlich entschieden wird, wirft stets die Frage auf, ob die Krise faktisch vor dieser rechtlichen Entscheidung überhaupt schon bestand oder ob sie als Konsequenz dieser Entscheidung, d.h. erst rechtlich hervorgebracht wurde. Bei der Erklärung des Ausnahmezustands geht es damit um mehr als nur um die Hervorbringung einer Krise des Rechts. Fraglich wird, ob die Krise des Rechts, die im Ausnahmezustand eingeleitet wird, die außerrechtliche Krise löst oder auslöst - ob mit der Einsetzung der Krise

3 Vgl. zum kognitiven Gehalt der Entscheidung über den Ausnahmezustand auch Menke 2004, 305-307. 
des Rechts auch die faktische Krise einsetzt oder zumindest mit hervorgebracht wird.

Diese Frage bleibt allerdings einer rechtlichen Prüfung zugänglich. In ihr wird das, was in der souveränen Erklärung der Ausnahme zusammengenommen wird - das Urteil über die faktische Lage und der Entschluss über den rechtlichen Zustand -, wieder getrennt. Heute bestehen insbesondere auf völkerrechtlicher Ebene Möglichkeiten zu einer solchen nachträglichen Beurteilung von Ausnahmezustandserklärungen und der in ihrer Folge ergriffenen Maßnahmen. Erklärt etwa ein Mitgliedsstaat des Europarats einen nationalen Ausnahmezustand und derogiert in diesem Zug die Europäische Menschenrechtskonvention (EMRK) gemäß deren Artikel 15, so ist der Europäische Gerichtshof für Menschenrechte (EGMR) befugt, die Rechtmäßigkeit dieser Derogation zu prüfen und sie gegebenenfalls für ungültig zu erklären. ${ }^{4}$ Die Überprüfung richtet sich darauf, ob faktisch eine unmittelbare Gefährdungslage bestand, zu deren Bewältigung die im rechtlichen Normalfall zulässigen Maßnahmen nicht hinreichten. Insofern ist die souverän getroffene rechtliche Entscheidung über die faktische Lage nicht definitiv (wie Schmitt postuliert), sondern rechtlich anfechtbar. Die völkerrechtliche Beurteilung der faktischen Lage erfolgt zwar wiederum im Rahmen des Rechts, denn in Frage steht die rechtliche Zulässigkeit. Maßgebend für diese Frage ist allerdings der Realitätsgehalt der in der Ausnahmezustandserklärung behaupteten Krise: Geprüft wird, ob in der souveränen Entscheidung über die Ausnahme die faktische Krise bloß rechtlich behauptet wurde oder ob sie auch außerrechtlich, d.h. vor der Erklärung des Ausnahmezustands gegeben war.

\section{I.2 Pandemie: Der Realitätsgehalt der Krise}

Völkerrechtlich kann die Prüfung dieser Frage nur verzögert erfolgen. Sie stellt sich allerdings bereits in dem Moment, in dem ein Ausnahmezustand eintritt, und wird zum Gegenstand einer gesellschaftlichen Debatte. Hinsichtlich dieser Debatte über die Berechtigung rechtlicher Ausnahmeregime

$4 \quad$ Eine solche Ungültigkeitserklärung erfolgte für Großbritannien nach einer Derogation der EMRK in der Folge der Anschläge vom 11. Septembers 2001 (vgl. dazu Grabenwarter und Pabel 2016, §2 Rn. 8). Allgemeiner zur Überprüfungsbefugnis des EGMR vgl. ebd., §2 Rn. 13 sowie Meyer-Ladewig, Nettesheim und von Raumer 2017, EMRK Art. 15 Rn. 7f. Neben dem EGMR beurteilt auch der Menschenrechtskommissar des Europarats die während der Derogation der EMRK im Rahmen eines nationalen Ausnahmezustands durchgesetzten Maßnahmen. 
stellt die Corona-Pandemie des Jahres 2020 eine Besonderheit dar. Die Besonderheit liegt in dem besonderen „Realitätsgehalt“, welcher der vor-rechtlichen Krise weithin attestiert wird. Ausdrücklich unterstrich etwa Slavoj Žižek in verschiedenen Beiträgen bereits zu Beginn der Pandemie die „reality of the threat“ (2020a, 75), den „Realitätsgehalt der Gefahr“ (2020b). Diese volle Realität der Epidemie („the full reality of the epidemic“; 2020a, 76) gelte es, so Žižek, zu akzeptieren. Die Zuschreibung von Realität lässt sich kaum durch eine sichtbare Evidenz der Gefahr erklären. So bemerkte Christoph Gusy: „Wer Politiker und Medien für Lügner hält, für den ist die Katastrophe nicht da. Denn es fehlt die Evidenz.“ (Gusy 2020) Erst als sich Mitte März die Fotografien der nächtlichen Leichentransporte in Bergamo verbreitet haben, wurde manchen die Pandemie sicht- und damit greifbar (vgl. Scherrer 2020). Hingegen bleibt das die Krankheit Covid-19 verursachende Virus SARS-CoV-2 selbst unsichtbar. Auch das Wissen über das Virus, das in den ersten Wochen sehr gering war (seither aber rasch und umfassend gewachsen ist), kann die frühe Zuschreibung von Realität nicht erklären; große Unsicherheit herrschte zu Beginn sowohl über die Übertragung des Virus als auch über seine Gefährlichkeit, insbesondere seine Mortalität für unterschiedliche Patient*innengruppen. Zwar können Unsichtbarkeit und Nichtwissen das Gefühl von Bedrohung steigern, doch die Zuschreibung einer Realität der Bedrohung lässt sich dadurch gerade nicht erklären. Ein wichtiger Grund für diese Realitätszuschreibung scheint mir weniger in der Frage von Sichtbarkeit und Wissen, sondern vielmehr im Aspekt der Natürlichkeit zu liegen: Der Realitätsgehalt wird darin gesehen, dass die Krise nicht als politisch konstruiert, ja nicht einmal als menschlich produziert wahrgenommen wird, sondern als eine natürlich gegebene erscheint - verursacht durch ein von jeder Entscheidung unabhängiges Stück Natur, durch ein Virus, und entfacht durch dessen Verbreitung. Als „natürlich“ verstehen wir das, was nicht durch unser Handeln hervorgebracht, sondern unabhängig von uns gegeben ist und uns äußerlich gegenübersteht. Die unabhängige Äußerlichkeit der physischen Natur lässt diese in einem besonderen Maß als wirklich, als von den Subjekten getrennte Objektivität erscheinen. Dass die Bedrohung durch das Virus als besonders real wahrgenommen wird, scheint mir vor diesem Hintergrund dadurch mitbewirkt, dass das Virus eine natürliche Prozessualität darstellt, die als kleinste Körper in unsere Körper, in unsere eigene Natur, einfällt und diese unsere Natur, damit unser Leben, gefährdet. ${ }^{5}$ Weil das 
Virus selbst nicht mobil ist und über unsere Körper übertragen wird, werden diese Körper, unser eigener wie die der anderen, zum Träger der Gefahr: Eine Bedrohung sind unsere Berührungen, unser Atem und die Spuren, die unsere natürlichen Körper im sozialen Raum hinterlassen. Verschiedentlich wurde die Pandemie vor diesem Hintergrund als eine Katastrophe der Natur bezeichnet. So sprach Drosten, wie erwähnt, am 11. März 2020 von einer in Zeitlupe ablaufenden „Naturkatastrophe“ (Drosten 2020c, 2). ${ }^{6}$

Die Wahrnehmung der Krise als natürliche Katastrophe hat - so meine These - die Akzeptanz der jüngst erklärten Ausnahmezustände und der in ihnen ergriffenen Maßnahmen erhöht. Eine Naturkatastrophe ist eine faktische Krise, die sich schwer bloß fingieren und behaupten ließe. Bei Katastrophen der Natur ist daher besonders evident, dass sie auch außerrechtlich, also vor der rechtlichen Erklärung von Ausnahmezuständen gegeben sind. Es bestehen in einem solchen Fall wenig Zweifel daran, dass der Ausnahmezustand auf eine faktisch vorliegende Krise reagiert und diese Krise nicht bloß rechtlich hervorbringt. Weil er damit seiner Funktion entspricht, eine Krisenreaktion zu sein, gewinnt ein solcher Ausnahmezustand Legitimität.

Diese Besonderheit der gegenwärtigen Ausnahmesituation tritt hervor, wenn man sie mit anderen jüngeren Ausnahmezuständen vergleicht, wie sie etwa von 2015 bis 2017 in Frankreich oder von 2016 bis 2018 in der Türkei bestanden. In beiden Fällen war die Erklärung des Ausnahmezustands eine Reaktion auf ein politisches Ereignis: In Frankreich auf die Terroranschläge in Paris vom November 2015, in der Türkei auf einen Putschversuch von Teilen des Militärs im Juli 2016. In beiden Fällen wurde zwar nicht die Realität dieser Ereignisse selbst in Frage gestellt; bezweifelt wurde hingegen, ob die Terroranschläge bzw. der Putschversuch jeweils eine nationale Krisenlage auslösten: einen „öffentlichen Notstand“, der „das Leben der Na-

der in der Wahrnehmung der Bedrohung durch die Corona-Krise einerseits und durch die Klimakrise andererseits und damit in der Bereitschaft besteht, auf die jeweilige Krise durch einschneidende Maßnahmen zu reagieren: Anders als die Effekte der Klimakrise kann das Virus alle unsere Körper direkt und dies nicht erst in einigen Jahren oder Jahrzehnten, sondern in ein paar Tagen und überall auf der Welt in gleicher Weise affizieren. Zu Unterschieden, v. a. aber Gemeinsamkeiten von Klima- und Corona-Krise vgl. auch Gabrysch 2020 .

6 Auch in der Politik wurde diese Bezeichnung übernommen. So nannte der Bayerische Ministerpräsident Markus Söder auf dem am 26.9.2020 virtuell abgehaltenen CSU-Parteitag die Corona-Krise „eine Art Naturkatastrophe“. 
tion“ bedroht.7 In Kritik geriet damit das Urteil über die faktische Lage, das mit den rechtlichen Erklärungen jeweils verbunden war. Steht so der „Realitätsgehalt“ der Krise in Zweifel, wird auch die Entscheidung für den Ausnahmezustand samt der in ihm ergriffenen rechtlichen Maßnahmen fragwürdig.

Vor diesem Hintergrund kann verständlich werden, inwiefern der in der gegenwärtigen Corona-Krise festgestellte hohe „Realitätsgehalt“ auch das Bewusstsein von Notwendigkeit und Legitimität der Maßnahmen erhöht. Anders als in Frankreich und in der Türkei ist das auslösende Ereignis kein politischer Akt, sondern eine natürliche Ansteckung. ${ }^{8}$ Im Unterschied zu einem politischen Ereignis - einem Putschversuch oder einem Anschlag entzieht sich ein Naturereignis als solches der (politischen) Deutung. Indem es sich ereignet, ohne etwas zu intendieren, ist es grund- und bedeutungslos. Weder „will“ es die bestehende Ordnung noch dominierende Wertvorstellungen angreifen. Die Frage, die sich bei einem Naturereignis daher nicht stellt, ist diejenige nach dem Feind. Dass ein (als solcher immer politischer) Feind bloß fingiert werde, kann daher nicht zur Debatte stehen. Ein natürliches Ereignis erscheint gerade dadurch als real, dass es sich nicht wie ein politischer Feind konstruieren lässt. Gerade aus der Unstrittigkeit, die durch ein als ,natürlich“ im Unterschied zu ,politisch“ eingestuftes Ereignis hervorgerufen wird, lässt sich politisch Kapital schlagen. So hat etwa in Ungarn Victor Orbán, der sich durch ein Notverordnungsgesetz weitgehende Befugnisse eingeräumt hat, Ende März 2020 gefordert, dass politische Debatten jetzt keinen Platz haben sollten und stattdessen eine Zeit der Einheit unabhängig von der Parteizugehörigkeit gekommen sei. ${ }^{9}$ Dass die Politik zurückstehen

7 So die Formulierung in dem die Ausnahme regelnden Art. 15 Abs. 1 EMRK. Die EMRK wurde von der Türkei am 18.5.1954 und von Frankreich am 3.5.1974 ratifiziert (vgl. European Treaty Series Nr. 005). Zur Kritik, dass im Ausnahmezustand Maßnahmen umgesetzt wurden, die sich nicht auf den anlassbezogenen Zweck (Beseitigung der durch die Terroranschläge bzw. den Putschversuch manifesten Bedrohung) richteten, vgl. mit Blick auf Frankreich Fauth 2018 und Wihl 2017, 68-80; mit Blick auf die Türkei Office of the United Nations High Commissioner for Human Rights 2018, §§46, 72, 92.

8 Gleichwohl sprach Präsident Emmanuel Macron am 16.3.2020 von einem Krieg, wenn auch von einem medizinischen: „Nous sommes en guerre, en guerre sanitaire certes." (Macron 2020) Auch Žižek (2020a, 45) spricht von einem „medical war“.

9 Bezeichnenderweise fielen die exekutiven Maßnahmen in Ungarn dann dadurch auf, dass sie sich weniger auf die Bekämpfung einer natürlichen Bedro- 
soll, mag gerade dann einleuchten, wenn die Bedrohung als natürliche Gegebenheit auftritt: Natur ist einfach „da“, ohne dass darüber erst entschieden würde.

Allerdings trifft dies auf die gegenwärtige Pandemie nicht zu: Die im März 2020 vielerorts erlassenen Ausnahmeregime waren nicht unmittelbar an eine natürliche Begebenheit, sondern an eine Entscheidung über die faktische Lage geknüpft: an die am 11. März erfolgte Deklaration der Pandemie durch die Weltgesundheitsorganisation (WHO). Die Entstehung dieser Entscheidung wird ambivalent beurteilt, was das Verhältnis von medizinischer Expertise und politischem Druck betrifft. Die Rolle der WHO ist stark umstritten und bisher nicht vollständig geklärt. Der WHO und ihrem Generalsekretär Tedros Adhanom Ghebreyesus wird, nicht nur von Seiten des US-Präsidenten Donald Trump (dessen Umgang mit der WHO wiederum kritisiert wird), besonders eine mangelnde politische Unabhängigkeit von China vorgeworfen: Die WHO habe sich zu sehr auf Informationen aus China gestützt und abweichende Informationen über Ansteckungswege aus Taiwan zunächst ignoriert; zudem steht in Kritik, dass die WHO ausdrücklich die Transparenz der Informationspolitik Chinas gelobt hat, obschon diese sehr zweifelhaft ist (vgl. Wurzel 2020). Die WHO-Entscheidung über die faktische Lage, so lässt sich diese Kritik zusammenfassen, ist - im oben erläuterten Sinn - zu wenig eine kognitive und zu sehr eine politisch bestimmte. Auf der anderen Seite wird dieser Entscheidung im Hinblick auf den Realitätsgehalt der Krise insofern Gewicht beigemessen, als sie nicht direkt von staatspolitischen Akteur*innen ausging: Das Urteil über die faktische Lage fällt hier mit dem Entschluss über den rechtlichen (Ausnahme-)Zustand nicht zusammen, sondern geht ihm voraus. Weil die Erklärung der WHO von den praktischen Entschlüssen der einzelnen Staaten getrennt ist, können sich die Staaten in der Legitimation ihrer rechtlichen Ausnahmemaßnahmen auf diese Erklärung stützen. Bevor ich im übernächsten Abschnitt auf diese nationalen Ausnahmezustände und damit auf die Phase der Bewältigung der Pandemie eingehe, möchte ich zunächst die Phase der Entstehung der Pandemie in den Fokus rücken und erläutern, inwiefern in ihr Natur und Gesellschaft in mehrerer Hinsicht zusammenwirken.

hung als auf die Bekämpfung politischer Gegner richteten - dass sie weniger die gesundheitliche Krise der Pandemie bewältigten als eine politische Krise der Demokratie produzierten. Vgl. Krökel 2020 sowie den Videobeitrag in der Sendung 10 vor 10 vom 24.3.2020, „Coronavirus: Bedrohung der Demokratie?", Schweizer Fernsehen SRF 2020. 


\section{Hervorbringung der Pandemie und Kriseneffekte der Maßnahmen}

\section{II.1Nicht nur Natur: Die Entstehung der pandemischen Ausnahmelage 2020}

Die Ansteckung, durch die das Virus SARS-CoV-2 vom Tier auf den Menschen übersprang und sich die Krankheit Covid-19 von Mensch zu Mensch verbreitet, ist ein natürlicher Prozess. Hingegen ist die pandemische Bedrohung nicht auf Natur zu reduzieren. ${ }^{10}$ Zwar ist das Virus natürlich entstanden, doch ist das Virus selbst keine Pandemie. Mit dem Begriff der Natur allein ist die Pandemie weder in ihrer Auslösung (i) noch in ihrer Verbreitung (ii) noch in ihren Folgen (iii) zu fassen. Dies möchte ich nachstehend erläutern, indem ich darauf fokussiere, wie sich der natürliche Prozess der Ansteckung mit ökonomischen Prozessen verbindet. Es soll deutlich werden, dass sich in den Phasen der Entwicklung hin zur Pandemie an entscheidenden Stellen die Grenze von Natur und gesellschaftlichem Handeln nicht scharf ziehen lässt, sondern die Krise der Pandemie sich erst aus deren Verbindung ergibt.

i) Die Auslösung der gegenwärtigen Pandemie geht aller Wahrscheinlichkeit nach auf ein menschliches Naturverhältnis zurück: auf die Interaktion des Menschen mit Nichtmenschlichem. Die Krankheit hat eine zoonotische Herkunft, das Virus wurde von Wildtieren auf Menschen übertragen. ${ }^{11}$ Begünstigt wird dieser Vorgang nicht bloß und nicht primär durch die schlichte Begegnung von Menschen mit nichtmenschlichen Tieren: Bewegen wir uns in einem Regenwald, ist die Wahrscheinlichkeit gering, in dieser biodiversen Umgebung in Kontakt mit einem jener Wildtiere zu geraten, das einen Virus auf uns übertragen kann. Erhöht wird die Wahrscheinlichkeit bei gezielter Jagd und Handel mit Wildtieren, d.h. in jenen Fällen, in denen etwas Natürliches (das den Erreger übertragende Tier) im Innern der Kul-

10 Für eine kritische Auseinandersetzung mit der „Natürlichkeit“ der Corona-Krise s. auch Hoppe 2020.

11 Die Herkunft des Coronavirus ist noch nicht geklärt; plausibel erscheint, dass neben Schuppentieren Fledermäuse eine Rolle spielten, weil diese mehr Coronaviren beherbergen als andere Tiere und einige dieser Viren auf den Menschen übergesprungen sind (vgl. Jones 2020). Zur Klärung der Frage nach der Herkunft durch phylogenetische Untersuchungen vgl. Sallard, Halloy, Casane, van Helden und Decroly 2020. 
tur (Architektur und Geschehen des Marktes) erscheint. Das größte Risiko eines Übersprungs des Erregers vom Tier auf den Menschen besteht hingegen dort, wo die Grenze Natur/Kultur nicht nur in der einen oder anderen Richtung überschritten wird (Mensch im Regenwald bzw. Wildtier auf dem Markt), sondern wo diese Grenze verschwimmt. Dazu kommt es im Bereich der Landwirtschaft. Entscheidend ist dabei, dass Menschen Landschaften mit geringer Biodiversität hervorbringen, in denen jene Arten, welche die Krankheit mit großer Effektivität auf Menschen übertragen (neben Fledermäusen vor allem Nagetiere), besonders stark vertreten sind (vgl. Gibb u.a. 2020 sowie Jones 2020). Solche durch den Menschen transformierte Ökosysteme bilden „interfaces“ zwischen Natur und Kultur, an denen es besonders leicht zur Übertragung (,spillover") von Tieren auf den Menschen kommt (vgl. Jones in Gill 2020). Zu diesen Gebieten, in denen die Biodiversität auf wenige Arten geschrumpft ist, die zugleich Krankheiten vermehrt übertragen, zählen nicht nur Städte, sondern auch landwirtschaftlich intensiv genutzte Flächen und Plantagen. Die Schaffung dieser Landschaften ergibt sich aus ökonomischer Rationalität: aus der höheren Produktivität monokultureller Agrarbetriebe. Die prekären ökonomischen Verhältnisse der in diesen Betrieben tätigen Menschen bilden einen weiteren ökonomischen Faktor, der den Ausbruch einer Epidemie, d.h. die regionale Verbreitung der Krankheit begünstigt. Denn der industriell-landarbeitenden Bevölkerung steht häufig ein nur mangelnder Gesundheitsschutz zur Verfügung. Von den durch die bestehende Agrarökonomie bedingten prekären Lebensverhältnissen lässt sich schließlich auch der zuvor genannte Fall einer Übertragung durch Jagd und Handel mit Wildtieren nicht trennen, insofern gerade die arme Landbevölkerung auf dieses zusätzliche Einkommen angewiesen und somit einer Ansteckung ausgesetzt ist (vgl. Nepstad in Tollefson 2020). ${ }^{12}$ Der wahrscheinlichste Ort für die Auslösung einer Epidemie besteht allerdings wie erwähnt dort, wo die Grenzen zwischen Natur und Kultur nicht nur überschritten, sondern durchlässig werden, indem der Anstieg von krankheitsübertragenden Wildtieren in monokulturellen Agrarlandschaften ein Produkt von Kultur ist. ${ }^{13}$

Zur Prävention von Epidemien wird daher die Regulierung der Abholzung tropischer Wälder und des Handels mit Wildtieren empfohlen (vgl. Dobson u. a. 2020).

13 Neben anderen hat Elisabeth Bronfen argumentiert, dass die Antwort auf die Pandemie nicht darin liegen kann, den Dualismus in Denken und Praxis fort- 
ii) Dieses Ineinandergreifen von Natur und Kultur wird auch in der globalen Verbreitung der Krankheit deutlich. Viren können sich nicht selbstständig reproduzieren. Es handelt sich bei ihnen nicht um Zellen und sie vollziehen keine eigenen Stoffwechselprozesse. Daher werden sie nicht zu den Lebewesen gezählt, sondern stehen an der Grenze zwischen Leben und Nichtleben: „Schwundstufen“ des zellulären Lebens, nämlich von diesem Leben abgekoppelte organische Strukturen. Zu ihrer Vermehrung sind diese viralen Strukturen auf Wirtszellen und deren Stoffwechsel angewiesen; nur in einer fremden Zelle ist die Kopie des viralen Erbmaterials möglich. Die Verbreitung der Viren erfolgt durch die Übertragung von einem Lebewesen auf ein anderes. Diese Ansteckungen sind, jeweils für sich betrachtet, schlicht natürliche Vorgänge; eine, mehrere oder auch eine Vielzahl von Ansteckungen ergeben allerdings noch keine Pandemie. Während eine Epidemie räumlich begrenzt ist, bezeichnet der Begriff der Pandemie „eine weltweite Epidemie“; ${ }^{14}$ betroffen ist von der Krankheit das ganze (griech. pan) Gebiet bzw. Volk (griech. demos). Bereits wann eine globale Betroffenheit vorliegt, ist eine Frage der Auslegung: Welche Fallzahlen und welcher Verbreitungsradius müssen dafür erreicht werden? Eine Pandemie ist insofern, wie erwähnt, keine schlicht vorliegende Gegebenheit, sondern sie wird (gesundheits)politisch erklärt, im gegenwärtigen Fall von der WHO. Auch dass der Realitätsgehalt der Pandemie, d.h. die Bedrohung durch das Virus, weithin anerkannt ist, bedeutet nicht, dass sich die Wirklichkeit der Pandemie auf Natur reduzieren lässt. Noch vor der Erklärung zur Pandemie, Ende Januar 2020, wies David Quammen darauf hin, dass die Epidemie kein bloßes Resultat natürlicher Kontingenz sei, sondern durch menschliche Aktivität in Gang gesetzt wurde: „It was - it is - part of a pattern of choices that we humans are making." (Quammen 2020) Mehrfach wurde betont, dass zur Entwicklung einer Pandemie wie der gegenwärtigen viele unterschiedliche Faktoren zusammenwirken müssen. ${ }^{15}$ Verglichen wurde die Pandemie mit dem Naturereignis eines „perfekten Sturms“, in dem disparate Wetterlagen aus verschiedenen Gebieten aufeinandertreffen und aus ihrer Vermengung eine extreme

zusetzen, d.h. Grenzen zwischen Natur und Kultur aufzurichten, indem eine Natur ohne Menschen imaginiert wird (vgl. Bronfen 2020a).

14 So die knappe Definition des Robert Koch-Instituts (RKI); https://www.rki. de/SharedDocs/FAQ/Pandemie/FAQ18.html (abgerufen am 8.10.2020).

15 So unterstrich Kate Jones im Interview vom 8. Juli 2020: „for an event like this to occur so many things have to line up exactly“ (Jones 2020). 
Kraft entwickeln. ${ }^{16}$ Der „perfekte Sturm“ der gegenwärtigen Pandemielage ist allerdings kein allein natürliches Ereignis. Denn zu den Bedingungen, unter denen sich die natürliche Ansteckung in kurzer Zeit an unterschiedlichsten Orten der Welt vollziehen und die Krankheit sich global ausbreiten kann, hat gesellschaftliches Handeln entscheidend beigetragen. In diesem Sinn formulierte der Veterinärepidemiologe Matthew Baylis gegenüber BBC News: „We've created almost a perfect storm here for the emergence of pandemics“ (Baylis in Gill 2020, Hervorh. J.H.). Auch dieses „pattern of choices“, das die pandemische Verbreitung mit ermöglicht hat, ist wesentlich eines der Ökonomie: Ohne globale Handels- und Tourismusströme, die Waren und Menschen transportieren, hätte die Verbreitung des Virus in diesem Ausmaß nicht stattfinden können. Nicht nur zu ihrer Vermehrung in Wirtszellen sind die Viren (mitunter) auf menschliche Träger angewiesen, sondern auch zu ihrer Verbreitung über alle Kontinente hinweg. Jean-Luc Nancy betonte, die Coronavirus-Pandemie sei auf jeder Ebene ein Produkt der Globalisierung (,a product of globalisation“), das deren ökonomische Charakteristika und Tendenzen hervortreten lasse: „It is an active, combative and effective freetrade agent“ (Nancy 2020). Die Verbreitung des Virus ist wie ein bildgebendes Verfahren dieser globalen, ökonomisch bedingten Mobilität. ${ }^{17}$

iii) Schließlich lässt sich die Pandemie nicht nur in ihrer Auslösung und Verbreitung, sondern auch in ihren Folgen für die Menschen nicht auf ein natürliches Phänomen reduzieren. Das gilt zunächst hinsichtlich der physischen Gesundheit der Betroffenen. Bereits in den ersten Wochen der Pandemie wurde klar, wie beschränkt die verbreitete Rede, alle säßen im selben Boot, auf die gegenwärtige Situation zutrifft. Zwar können alle an der durch das Virus verursachten Infektion erkranken, die gesundheitlichen Folgen sind allerdings nicht für alle gleich. Die Ungleichheit steht dabei nicht allein in Abhängigkeit von Alter und Vorerkrankungen, sondern auch von Herkunft und Hautfarbe. Die Toten der Pandemie sind in erschütternder Weise auch zu einem bildgebenden Verfahren bereits existierender Ungleichheiten geworden, indem sie diese Ungleichheiten hinsichtlich des Zugangs zu me-

16 Vgl. etwa Žižek 2020a, Kapitel 3: „Towards a Perfect Storm in Europe“, 2936.

Vgl. auch Elisabeth Bronfen, die die Verbreitung als Index systemischen Fehlverhaltens liest: Sie vergleicht das Virus „mit dem Spurensicherungspulver an einem Tatort: Es hat systemische Vergehen globaler kapitalistischer Kultur sichtbar gemacht." (Bronfen 2020b) 
dizinischer Versorgung und damit der Überlebenschancen sichtbar gemacht haben..$^{18}$ Die gesundheitlichen Folgen der Pandemie sind insofern nicht bloß natürlich, als sie durch sozio-ökonomische Bedingungen mit bestimmt und mit bewirkt sind.

Was ich als erste Phase der Krise bezeichnet habe - die Entstehung der Pandemie und die von ihr ausgehende gesundheitliche Gefahr -, ist in allen genannten Aspekten mit gesellschaftlichem Handeln verknüpft. Dieses Handeln, das zeitlich vor der Intervention durch Krisenmaßnahmen und damit vor der Phase der Bewältigung liegt, trägt zu jener Lage bei, die ich hier die "faktische Krise“ genannt habe: die globale Verbreitung des Virus und der Krankheit Covid-19. Allerdings resultieren die Folgen der Pandemie, gerade in einer globalen Perspektive, nicht allein aus dieser faktischen Krise (und damit aus der ersten Phase), sondern auch aus den rechtlichen Maßnahmen, die in Ausnahmezuständen zur Bewältigung der Pandemie ergriffen werden (und damit aus der zweiten Phase der Krise). Diese Maßnahmen der Krisenintervention zielen auf die ökonomische Lage und haben wiederum ökonomische Konsequenzen, die Ungleichheiten verstärken. In einem letzten Schritt wende ich mich den problematischen Effekten dieser Maßnahmen zu und frage danach, inwiefern dieses Handeln der Intervention die Krise nicht nur löst, sondern zugleich mit hervorbringt.

\section{II.2 Bewältigung als Teil des Problems: Zur Krisenproduktivität der Maßnahmen}

Die Maßnahmen, die weltweit im Rahmen von nationalen Ausnahmezuständen zum Zweck der Eindämmung des Virus bzw. der Covid-19-Erkrankung ergriffen wurden (vgl. Bjørnskov und Voigt 2020), sind rechtlich einschneidend. Deutschland hat formal rechtlich keinen Ausnahmezustand bzw. Notstand erklärt. Die unterschiedlichen Notstandsbestimmungen des deutschen Grundgesetzes (innerer Notstand, Verteidigungsfall, Spannungsfall, [Natur-]Katastrophenfall) sind als Reaktion auf die Bedrohung durch das Virus „nicht einschlägig und - soweit anwendbar - nicht hilfreich“; ein genereller Notstandsvorbehalt ist im Grundrechtsteil des Grundgesetzes (anders als noch in der Weimarer Verfassung mit ihrem Artikel 48) nicht vorhanden (Ipsen 2020, 132 sowie 122 und 127). Gleichwohl wurden auch in Deutsch-

18 Vgl. für die USA die Daten des nationalen Gesundheitsinstituts Centers for Disease Control and Prevention (CDC) 2020 sowie am Beispiel von Louisiana die ausgewertete Studie von Price-Haywood u. a. 2020. 
land angesichts der Pandemie einschneidende außerordentliche Maßnahmen erlassen, die es nahelegen, hier den „ersten landesweiten Ausnahmezustand[] in der Geschichte der Bundesrepublik" zu sehen (ebd., 119). Zu den Maßnahmen gehören insbesondere Grundrechtseinschränkungen, die nach dem Verfassungsrechtler Christoph Möllers den „massivste[n] kollektive[n] Grundrechtseingriff in der Geschichte der Bundesrepublik" bedeuten (Möllers 2020a). Diese Einschränkungen geschahen dabei nicht willkürlich, sondern folgten aus einer Abwägung zwischen konfligierenden Grundrechten. So richteten sich die in Deutschland beschlossenen Einschränkungen etwa der Versammlungsfreiheit (Art. 8 Abs. 1 GG) darauf, „die Ausbreitung einer Krankheit zu verhindern und damit das Recht bisher nicht infizierter Dritter auf Leben und körperliche Unversehrtheit zu schützen (Artikel 2 Absatz 2 Satz 1 Grundgesetz, GG)“ (Gesellschaft für Freiheitsrechte 2020). Einen Bruch markieren diese Einschränkungen insofern nicht so sehr hinsichtlich ihrer Begründung, sondern eher hinsichtlich ihres Umfangs (vgl. ebd.), v. a. aber hinsichtlich ihrer Entstehung: Weitgehend ohne parlamentarische Verfahren zu durchlaufen, wurden sie durch die Exekutive in Verordnungen gebracht - wobei dieses demokratisch bedenkliche Ruhen der Parlamente weder aus Notwendigkeit erfolgte noch ersichtliche Vorteile brachte (vgl. Möllers 2020b, 272f.). Zu den hier tangierten Freiheitsrechten gehörten dabei die Bewegungsfreiheit (Quarantäne), die Versammlungsfreiheit (Demonstrationen), die Vereinsfreiheit, die Religionsfreiheit, die Unverletzlichkeit der Wohnung sowie mit Blick auf Besuchsverbote das allgemeine Persönlichkeitsrecht. Die gesetzliche Grundlage für die einschränkenden Maßnahmen bildet das Infektionsschutzgesetz (IfSG), insbesondere dessen Paragraphen 5 sowie 28 bis $32{ }^{19}$ Kritisiert wurde das in diesem Jahr angepasste Infektionsschutzgesetz einerseits für seine polizeirechtlich anmutende Schärfe und die Weite seiner Ermächtigung, die an den Ausnahmeartikel 48 der Weimarer Verfassung erinnere (vgl. Frankenberg 2020); andererseits wurde eingewandt, dass das Gesetz für die in diesem Jahr faktisch ergriffenen Maßnahmen keine ausreichende rechtliche Grundlage biete

19 Vgl. den Gesetzestext unter https://www.gesetze-im-internet.de/ifsg; zuletzt geändert wurde am 19.6.2020 Paragraph $5 \mathrm{zu}$ „Epidemische Lage von nationaler Tragweite“ (abgerufen am 8.10.2020). In der mit Paragraph 5 geschaffenen Befugnis zur Erlassung von Rechtsverordnungen sieht Stephan Rixen eine Überschreitung der durch das Grundgesetz (Art. 80 I 2 GG) gegebenen Grenzen; hierzu und insgesamt zu den Neuregelungen des Infektionsschutzgesetzes vgl. Rixen 2020. 
(vgl. Möllers 2020a). Auf diese Fragen soll hier im Einzelnen nicht eingegangen werden, sondern ein allgemeineres Charakteristikum der gegenwärtigen Maßnahmen in den Fokus gerückt werden.

Anders als in rechtlichen Ausnahmesituationen, denen eine politische Bedrohung zugrunde liegt (vgl. oben I.2), werden grundrechtlich verbürgte Freiheiten wie die Versammlungsfreiheit aktuell nicht eingeschränkt, weil sie missbräuchlich genutzt werden könnten, etwa zur Durchführung von Anschlägen, Umstürzen oder zu anderen Zwecken, die die kollektive Freiheit bzw. die „freiheitliche demokratische Grundordnung “ ${ }^{\text {“20 }}$ gefährden. Es ist derzeit nicht der Missbrauch der Freiheitsrechte, sondern - unabhängig vom jeweiligen Ziel - schlicht ihr Gebrauch, der als Bedrohung erscheint; nicht wozu Freiheitsrechte ausgeübt werden, sondern dass sie ausgeübt werden, bildet das Problem. ${ }^{21}$ Dabei wird Freiheit in dem basalen Sinn problematisch, den Hobbes in seinem Konzept der Freiheit vor Augen hatte: als Freiheit der Bewegung. ${ }^{22}$ Eingeschränkt werden die Rechte, um die Bewegung und damit den Kontakt der menschlichen Körper zu regulieren. ${ }^{23}$ Diese - somit breitflächige - Einschränkung ist zunächst egalitär: Alle Körper werden in gleicher Weise reguliert; zwar auch in Abhängigkeit davon, ob eine Covid-19-Infektion vorliegt oder wahrscheinlich ist, doch ohne Ansehen der Person. Eine explizite Fokussierung auf „Gefährder*innen“ und damit ein präemptiver Fokus auf bestimmte (religiöse, nationale u. a.) Bevölkerungsgruppen findet so zumindest weniger statt als in anderen Fällen. ${ }^{24}$ Doch selbst wenn die Maßnahmen insofern egalitärer sein mögen, als sie die Rechte aller betreffen, treffen sie doch nicht alle gleich.

20 Vgl. zu diesem Konzept und seiner Geschichte in der Bundesrepublik Deutschland Schulz 2019.

21 Eine Ausnahme bildet jener - hier unbedrohliche - Gebrauch der Rechte, der in ihrem Nichtgebrauch besteht (vgl. dazu Hamacher 2006).

22 Vgl. Hobbes 1991, Kap. 21, 163; eine instruktive Erläuterung des Freiheitsverständnisses in Hobbes' Leviathan gibt Skinner 2008, Kap. 3, 81-120.

23 Für eine kritische Beurteilung der Ausgangsverbote in sechs deutschen Bundesländern im Frühjahr 2020 vgl. aus verfassungsrechtlicher Perspektive Schmitt 2020.

24 Zur Ungleichbehandlung muslimischer Bevölkerung im Rahmen des Ausnahmezustands in Frankreich (2015-2017) bzw. des daran anschließenden Gesetzes zur „Stärkung der inneren Sicherheit und des Kampfes gegen den Terrorismus"vgl. Fauth 2018 und Wihl 2017. 
Die Differenz ist wiederum mitunter ökonomisch bedingt und ergibt sich hier auf verschiedenen Ebenen. Erstens wurde von vielen Kommentator*innen mit Recht darauf hingewiesen, dass das Zuhause-Bleiben für die ökonomisch Privilegierten - die womöglich auch noch über Zweitwohnsitze auf dem Land verfügen - nicht dieselbe Einschränkung bedeutet wie für prekär Situierte in kleinen Wohnungen oder für Geflüchtete, die sich in Lagern Räume von nur wenigen Quadratmetern teilen. Zweitens, und damit verbunden, bedeutet auch der Stillstand der wirtschaftlichen Beschäftigung für die ökonomisch besser Gestellten eine geringere Bedrohung, da die Anstellungen sicherer und/oder die finanziellen Reserven größer sind. In armen Ländern, in denen viele Menschen einen Großteil ihres Einkommens für die Ernährung aufwenden, machen sich finanzielle Ausfälle hingegen sofort existentiell bemerkbar. ${ }^{25}$ Drastisch ist die Situation in Geflüchtetenlagern, etwa dem weltgrößten in Bangladesch, dem Lager Kutupalong. Während des bis August 2020 dauernden Lockdowns konnten die Bewohner*innen aufgrund der Ausgangssperren keine Tagelohnarbeiten mehr verrichten und verloren dadurch das Einkommen, um sich neben den gestellten Grundnahrungsmitteln (Reis, Hülsenfrüchte, Öl) auch Gemüse, Fisch oder Eier kaufen zu können. ${ }^{26}$ Diese zwei Punkte betreffen die Einschränkung der jeweils eigenen Freiheit der Menschen, die innerhalb eines Landes gleichmäßig erlassen werden und in den privaten Lebens- wie in den beruflichen Tätigkeitsverhältnissen ökonomisch ungleiche Folgen haben.

Doch nicht nur innerhalb von Staaten, sondern auch zwischen ihnen führen die ergriffenen Maßnahmen dazu, bereits bestehende Ungleichheiten zu verschärfen. Finanzpolitische Interventionen, die die Bevölkerung entlasten, sind nur in wenigen Staaten als Reaktion auf die ökonomische Krise möglich; viele Länder des globalen Südens sind hingegen für solche Maßnahmen zu hoch verschuldet. ${ }^{27}$ Nicht nur hinsichtlich der Verschuldung erwächst ökonomische Ungleichheit aus zwischenstaatlicher Verflechtung. Das genannte Problem der Ernährungsunsicherheit etwa verstärkt sich da-

25 Die stärkste Zunahme von Ernährungsunsicherheit im ersten Halbjahr 2020 ist in Ländern in Süd- und Südostasien sowie in Afrika südlich der Sahara zu verzeichnen (vgl. United Nations 2020, 8).

26 Vgl. den Rundfunkbeitrag in der Sendung Echo der Zeit vom 24.8.2020, „Die Rohingya-Flüchtlinge waren komplett eingesperrt", Schweizer Radio SRF 2020. 
durch, dass die Rücküberweisungen von in reicheren Staaten arbeitenden Migrant*innen an ihre Angehörigen in den Heimatländern wegen der im Rahmen der Pandemiebekämpfung erfolgten Arbeitsplatzverluste ausfielen. ${ }^{28}$ Zudem führen die Unterbrechungen im globalen Handel und in den Lieferketten zur Intensivierung von Nahrungsunsicherheiten, wobei insbesondere die Unterernährung von Kindern dramatisch wächst. ${ }^{29}$ Hier zeigt sich ein weiterer Aspekt des in beiden zeitlichen Phasen der gegenwärtigen Krise vorliegenden Zusammenhangs von Natur und Gesellschaft. Er liegt nicht in der ersten Phase, der Entstehung der Pandemie (die sich, wie gesehen, nicht allein natürlich, sondern auch gesellschaftlich vollzieht), sondern in der zweiten Phase, der Bewältigung der Pandemie, in der das gesellschaftliche Handeln - die rechtlichen Einschränkungen der Ökonomie - sich auf die materielle Subsistenz, die Erhaltung der natürlichen Existenz von Menschen auswirkt. Die Unterernährung, die sich in den Körpern gesundheitsund lebensgefährdend materialisiert, kann nicht als ein bloß natürliches Phänomen begriffen werden, insofern sie nicht aus einer als natürlich zu fassenden Ursache resultiert; denn mit dem Virus und seiner Verbreitung hat sie unmittelbar nichts zu tun. Sie folgt vielmehr aus den Maßnahmen, die mitunter an entfernten Orten der Welt getroffen werden und zu einer Rezession führen, die im globalen Süden existentielle Folgen hat. Indem sich die gesundheits- und lebensgefährdende Unterernährung aus der rechtlichen Einschränkung der Ökonomie in anderen Ländern ergibt, ist es hier nicht allein die eigene eingeschränkte Freiheit, sondern auch die eingeschränkte Freiheit der anderen, die die Ungleichheit und die Gefährdung des eigenen Lebens erhöht. Die Einschränkung der Freiheit, die in den einen Ländern Leben retten soll, kostet in anderen Ländern Leben, das bereits prekär ist. Auch auf diese zwischenstaatlichen Folgen der freiheitseinschränkenden Maßnahmen ist daher mit staatlichen und zwischenstaatlichen Maßnahmen der Solidarität zu reagieren. Weil die Bekämpfung der Krise allerdings einen stark nationalen Fokus hat und die einzelnen Staaten - wie ganz zu Beginn des Aufsatzes angesprochen - sich auf die je eigenen Fallzahlen und den je

28 Vgl. dazu die Angaben des Internationalen Währungsfonds, Sayeh und Chami 2020.

29 Schätzungen gehen davon aus, dass infolge der Pandemiebekämpfungsmaßnahmen zu den 47 Millionen Kindern unter fünf Jahren, die vor der Pandemie an akuter Unterernährung litten, im Jahr 2020 weitere 6,7 Millionen Kinder unter fünf Jahren hinzukommen (vgl. Headey, Heidkamp und Osendarp u. a. 2020). 
eigenen Landeserfolg konzentrieren, ist in der Diskussion über die Maßnahmen wenig im Blick, welche Folgen sie für Menschen in anderen Ländern und Kontinenten haben.

\section{Schluss: Klassisches und verschwörungsmythisches Denken der Krise}

Dem nationalen Fokus in der Bekämpfung der Krise entspricht, dass die Menschen, die in Deutschland gegen die staatlich ergriffenen Maßnahmen protestieren, dies vor allem im Hinblick auf eine für sie selbst reklamierte Betroffenheit tun. Gegen die Einschränkung ihrer Freiheit wenden sich in Deutschland diverse Gruppen von „Querdenker*innen“ (eine lose Verbindung von Menschen, die insbesondere die Beschränkung von Grundrechten kritisieren), Verschwörungsmythiker*innen und anderen „Corona-Kritiker*innen“. Erbittert kämpfen sie gegen die Maßnahmen und verstoßen in großen Demonstrationen gezielt gegen die verordneten Einschränkungen. Gemeinsam ist diesen unterschiedlichen Gruppen nicht die politische Position, für die sie einstehen, sondern wogegen sie sich wenden: die Ablehnung der staatlichen Maßnahmen zur Eindämmung der Krankheit Covid-19 (vgl. Deutschlandfunk 2020a). Unter den verschiedenen Motiven für diese Ablehnung lassen sich zwei konträre Stoßrichtungen unterscheiden: Die eine Richtung leugnet nicht die gesundheitliche Gefahr der Pandemie, bezweifelt allerdings ihre Herkunft. Sie glaubt, die Pandemie sei gezielt hervorgebracht, das Virus also mit Absicht verbreitet oder gar erzeugt worden: etwa im Auftrag von Bill und Melinda Gates (um Impfprojekte und die Injektion von Mikrochips zu ermöglichen), im Auftrag von George Soros (um Donald Trump zu Fall zu bringen) oder durch chinesische Labore (vgl. Schröder 2020). Dagegen bezweifeln Gruppierungen der zweiten Richtung, zu der etwa die „Querdenker*innen“ gehören, nicht die Herkunft der Pandemie, aber ihre Gefährlichkeit: Die Bedrohung durch das Virus sei vergleichbar mit jener durch das Grippevirus und werde daher bewusst übertrieben, um durch staatliche Freiheitseinschränkungen ein neues Beherrschungsregime zu etablieren (vgl. Deutschlandfunk 2020b). In ihren Ansichten über Herkunft und Gefährlichkeit des Virus gehen die beiden Richtungen auseinander. Was sie hingegen eint, ist die Vorstellung, dass die mit dem Virus verbundene Krise durch das Handeln einiger Mächtiger hervorgebracht wurde: durch eine intendierte Verbreitung des Virus zur realen Pandemie (so die erste Richtung) oder durch die Interventionen, die sich an eine bloß $d r a-$ 
matisierte Pandemie knüpfen (so die zweite Richtung). Der ersten Richtung zufolge entsteht die Krise durch die Produktion der gesundheitlichen Pandemie, der zweiten Richtung zufolge durch die Suspension der sozialen Normalität. Beide Richtungen streiten ab, dass die Krise selbst in irgendeiner Weise auf Natur zurückgeht - d.h. auf etwas, das in Handeln nicht aufgeht. Weil somit beiden die Krise als gezielte Maßnahme erscheint, richten sich ihre Forderungen häufig auf eine sofortige Rücknahme der Krise: auf ein „Ende der Pandemie“. ${ }^{30}$

Dass wir gegenwärtig in einer Krise leben, wird von beiden Richtungen nicht bestritten, sondern ist vielmehr der Grund, warum sie auf die Straße gehen. Allerdings haben sie auf diese Krise eine ganz andere Sichtweise als beispielsweise jene eingangs genannte von Drosten (und dies nicht nur im Hinblick auf die ebenso absurden wie gefährlichen antisemitischen, rassistischen und völkischen Ideen, die sich in manchen Gruppierungen beider Richtungen finden lassen): In der Sichtweise dieser Gruppierungen gibt es in der gegenwärtigen Krise nicht eine Phase vor dem Maßnahmehandeln, die das Handeln dringlich machte, und eine Phase des Handelns, in der auf die vorliegende Krise reagiert wird. Vor dem Handeln, so diese Sichtweise, besteht keine Krise, sondern die Krise ist allein durch das Handeln produziert; und weil das Handeln die Krise erst herbeiführt, führt es auch nicht in einen Zustand nach der Krise. Das Maßnahmehandeln erscheint in dieser Perspektive nicht als Versuch, die Krise zu lösen, sondern allein als deren Auslösung. Ziel des Handelns ist nicht die Bewältigung der Krise, sondern ihre Hervorbringung. Diese Sichtweise ist in verheerender Weise falsch, weil sie annimmt, dass es gar keine bedrohliche Situation gäbe, wenn nicht gehandelt worden wäre, und dass die Krise deshalb allein dadurch zu beheben ist, dass alle Maßnahmen fallen gelassen werden.

Die einem „klassischen“ Verständnis der Krise, für das hier neben Drosten auch Koselleck stand, zugrunde liegende Differenz zwischen der Entstehung der Pandemie und den Maßnahmen zu ihrer Bewältigung, wird von den genannten Corona-Kritiker*innen eingeebnet: entweder, wie in der ersten Richtung, weil die Entstehung der Krise in Wahrheit nichts anderes sei als eine Maßnahme (die Pandemie sei gezielt erzeugt); oder, wie

30 Vgl. zu dieser Forderung Rosendorff 2020 sowie Bethke 2020. Von einer fingierten Epidemie („invention of an epidemic“) sprach in einer frühen Stellungnahme vom 26. Februar 2020 auch Giorgio Agamben (vgl. Agamben 2020). 
in der zweiten Richtung, weil die zur Bewältigung ergriffenen Maßnahmen in Wahrheit nichts anderes seien als der alleinige Grund ihrer Entstehung. In der einen wie in der anderen Richtung fällt die Entstehung der Krise mit der ergriffenen Maßnahme in eins. Dagegen ging dieser Aufsatz im Sinne des klassischen Verständnisses der Krise davon aus, dass das interventionistische Maßnahmehandeln, wie es insbesondere in der Folge einer staatlich erklärten Ausnahmelage einsetzt, den Trennungspunkt zweier Krisenabschnitte bildet. Allerdings wurde dieses klassische Verständnis dahingehend irritiert und modifiziert, dass mit Blick auf die gegenwärtige Krise die beiden Phasen differenziert verstanden werden können. Einerseits kam hinsichtlich der Entstehung das krisenfördernde Handeln in Betracht, das vor der Intervention stattfand und in dem sich Naturprozess und Gesellschaftshandeln verbinden. Andererseits wurde hinsichtlich der Bewältigung erläutert, inwiefern die Maßnahmen selbst, allerdings in ganz anderer Weise als von den genannten Gruppen der Corona-Kritiker*innen moniert, krisenproduktive Effekte haben.

Der Zusammenhang von natürlichem Prozess und gesellschaftlichem Handeln ergab sich im Hinblick auf die gegenwärtige Pandemie auf zwei Ebenen. Zum einen lässt sich die Entstehung der Covid-19-Pandemie nicht auf ein natürliches Phänomen reduzieren, stellt aber zugleich auch kein Ereignis dar, das sich allein aus gesellschaftlichem Handeln erklärt; denn die Reproduktion und Übertragung des Virus ist nicht unser Vollzug, sondern vollzieht sich in und durch uns hindurch, ohne dass wir über diese Prozesse unmittelbar verfügen könnten. Diese Unverfügbarkeit, die als ein Merkmal natürlicher (Katastrophen-)Ereignisse gilt, zeigt sich in der gegenwärtigen Krise auch darin, dass wir zwar handelnd auf sie einwirken, sie aber nicht entscheiden, d.h. nicht einfach zurücknehmen können. Zum anderen ist die Krisenbewältigung, die mit rechtlichen Mitteln in Ausnahmezuständen erfolgt, zwar zunächst allein als gesellschaftliches (wenn auch nicht demokratisches) Handeln zu verstehen. Doch gerade in den Aspekten, in denen die Krisenreaktion in Krisenproduktion umschlägt, wird vermittelt über die Verschärfung von Ungleichheit auch das (natürliche) Leben der Menschen affiziert und beschädigt: Die rechtlichen Einschränkungen, die der Sicherung von Leben und Gesundheit (der einen Menschen am einen Ort) gelten, bringen Leben und Gesundheit (der anderen Menschen an anderen Orten) in Gefahr.

Auf beiden Ebenen, auf der Ebene der Entstehung der Pandemie wie auf der Ebene der rechtlichen Krisenbewältigung, wird dabei ein ökono- 
mischer Zusammenhang von natürlichem Prozess und gesellschaftlichem Handeln sichtbar: Während den Naturprozessen, die den Ausbruch der Pandemie begünstigen, Entscheidungen („,choices“) über die ökonomische Produktion zugrunde liegen, haben die rechtlichen Krisenbewältigungsmaßnahmen, die sich auf die Unterbrechung der Ökonomie richten, krisenproduktive Konsequenzen, die sich direkt auf Natur, auf die Körper und das (Über-)Leben von Menschen auswirken. Die gegenwärtige Krise, in der natürliches Geschehen, gesellschaftliches Handeln und Entscheiden untrennbar verstrickt sind, erweist sich somit als eine doppelte: zum einen als eine Krise, die sich aus menschlichen Naturverhältnissen entfaltet; zum anderen als eine Krise, die durch Ausnahmeentscheidungen gleichermaßen bewältigt wie verschärft und produziert wird. Demgegenüber müsste gelingendes Krisenhandeln insofern ein anderes Naturverhältnis bedeuten, als es sich zu dem in Beziehung setzt, was sich in ihm vollzieht und zugleich einer vollständigen Beherrschung entzogen bleibt.

\section{Literatur}

Agamben, Giorgio. 2020. „The state of exception provoked by an unmotivated emergency“. position politics, 26.2.2020. http://positionspolitics.org/giorgio-agamben-the-state-of-exception-provoked-by-an-unmotivated-emergency (abgerufen am 30.8.2020).

Bethke, Hannah. 2020. „Tag der Wutbürger“. Frankfurter Allgemeine Zeitung online, 2.8.2020. https://www.faz.net/aktuell/feuilleton/debatten/corona-leugner-demonstrieren-in-berlin-tag-der-wutbuerger-16887060.html (abgerufen am 30.8.2020).

Bjørnskov, Christian, und Stefan Voigt. 2020. „The State of Emergency Virus“. Verfassungsblog, 19.4.2020. https://verfassungsblog.de/the-state-of-emergency-virus (abgerufen am 30.8.2020).

Bronfen, Elisabeth. 2020a. „Schlägt Gaia zurück?“ Tages-Anzeiger. Das Magazin, 22.8.2020. https://www.tagesanzeiger.ch/schlaegt-gaia-zurueck-991428294331 (abgerufen am 30.8.2020).

Bronfen, Elisabeth. 2020b. „Statistiken mögen erhellend sein - helfen aber emotional nicht weiter“. Süddeutsche Zeitung, 22.8.2020. https://www.sueddeutsche. de/kultur/interview-bronfen-pandemie-kulturgeschichte-1.4998015 (abgerufen am 30.8.2020).

Centers for Disease Control and Prevention (CDC), https://www.cdc. gov/coronavirus/2019-ncov/community/health-equity/race-ethnicity.html?CDC AA refVal=https\%3A\%2F\%2Fwww.cdc.gov\%2Fcoronavirus\%2F2019-ncov\%2Fneed-extra-precautions\%2Fracial-ethnic-minorities.html\#anchor 1595551043298 (abgerufen am 8.10.2020). 
Deutschlandfunk. 2020a. „Corona-Demonstrationen: Positionen und Protagonisten“. 3.8.2020. https://www.deutschlandfunk.de/covid-19-pandemie-corona-demonstrationen-positionen-und.2897.de.html?dram:article id=476457\#Forderungen (abgerufen am 4.10.2020).

Deutschlandfunk. 2020b. „Hitzige Debatte über Corona-Maßnahmen“. 9.8.2020. https://www.deutschlandfunk.de/kampf-gegen-covid-19-hitzige-debatte-ueber-corona-massnahmen.2897.de.html?dram:article $\mathrm{id}=482020$ (abgerufen am 4.10.2020).

Dobson, Andrew P., Stuart L. Pimm, Lee Hannah u. a. 2020. „Ecology and economics for pandemic prevention“. Science 369 (6502): 379-381.

Drosten, Christian. 2020a. „Drosten: „Pandemie wird jetzt erst richtig losgehen““. Frankfurter Allgemeine Zeitung online, 23.9.2020. https://www.faz. net/aktuell/gesellschaft/gesundheit/coronavirus/virologe-drosten-pandemie-wird-jetzt-erst-richtig-losgehen-16968092.html (abgerufen am 4.10.2020).

Drosten, Christian, im Gespräch mit Inga Barthels. 2020b. „Wir sind vielleicht gerade dabei, unseren Vorsprung zu verspielen““. Der Tagesspiegel online, 22.4.2020. https://www.tagesspiegel.de/politik/virologe-drosten-sieht-lockerungen-skeptisch-wir-sind-vielleicht-gerade-dabei-unseren-vorsprung-zu-verspielen/25765460.html (abgerufen am 4.10.2020).

Drosten, Christian. 2020c. „Coronavirus-Update Folge 11: Wir müssen jetzt gezielt handeln“. Norddeutscher Rundfunk, 11.3.2020. https://www.ndr.de/nachrichten/info/coronaskript122.pdf (abgerufen am 30.8.2020).

Fauth, Lea. 2018. „Frankreich: Der Ausnahmezustand als Regelfall“. Blätter für deutsche und internationale Politik 63 (1): 9-12.

Frankenberg, Günter. 2020. „Covid-19 und der juristische Umgang mit Ungewissheit“. Frankfurter Allgemeine Zeitung online, 24.4.2020. https://www.faz.net/ einspruch/covid-19-und-der-juristische-umgang-mit-ungewissheit-16740090. html?GEPC=s3\&premium =0x639c9e282563fa1131bdfc65b55c3243 (abgerufen am 30.8.2020).

Gabrysch, Sabine, im Gespräch mit Georg Ehring. 2020. „Corona und Klimawandel. Epidemiologin: Haben erlebt, wie es aussieht, wenn eine Krise ernst genommen wird“. Deutschlandfunk, 18.8.2020. https://www.deutschlandfunk.de/corona-und-klimawandel-epidemiologin-haben-erlebt-wie-es.697.de.html?dram:article $\mathrm{id}=482563$ (abgerufen am 3.10.2020).

Gesellschaft für Freiheitsrechte. 2020. „Corona und Grundrechte: Fragen und Antworten“, 23.3.2020. https://freiheitsrechte.org/corona-und-grundrechte/\#1 (abgerufen am 30.8.2020).

Gibb, Rory, David W. Redding, Kai Qing Chin, Christl A. Donnelly, Tim M. Blackburn, Tim Newbold und Kate E. Jones. 2020. „Zoonotic host diversity increases in human-dominated ecosystems", Nature 584: 398-402.

Gill, Victoria. 2020. „Coronavirus: This is not the last pandemic“. BBC News, 6.6.2020. https://www.bbc.com/news/science-environment-52775386 (abgerufen am 8.10.2020). 
Grabenwarter, Christoph, und Katharina Pabel, Hrsg. 2016. Europäische Menschenrechtskonvention. Ein Studienbuch. München: C.H. Beck.

Gusy, Christoph. 2020. „Was wir von Gütersloh für das Ordnungsrecht lernen können“. Verfassungsblog, 24.6.2020. https://verfassungsblog.de/was-wir-von-gueterslohfuer-das-ordnungsrecht-lernen-koennen (abgerufen am 30.8.2020).

Hamacher, Werner. 2006. „Vom Recht, Rechte nicht zu gebrauchen“. In Urteilen/ Entscheiden, herausgegeben von Cornelia Vismann und Thomas Weitin, 269290. Fink: München.

Headey, Derek, Rebecca Heidkamp, Saskia Osendarp u.a. 2020. „Impacts of COVID-19 on childhood malnutrition and nutrition-related mortality". The Lancet 396 (10250), August 2020: 519-521.

Heller, Jonas. 2018. Mensch und Maßnahme. Zur Dialektik von Ausnahmezustand und Menschenrechten. Weilerswist: Velbrück Wissenschaft.

Hobbes, Thomas. 1991. Leviathan oder Stoff, Form und Gewalt eines kirchlichen und bürgerlichen Staates, herausgegeben und eingeleitet von Iring Fetscher. Frankfurt/M.: Suhrkamp.

Hoppe, Katharina. 2020. „Natur“. In Kritische Theorien in der Pandemie. Ein Glossar zur Corona-Krise. 29.3.2020. Vortrag online verfügbar unter: https://www. youtube.com/watch?v=KcWoQ8KdMa8\&list=PLvqj5O3ibOM7eYWSTZc-uMS6Ksse6Ed D\&index=14 (abgerufen am 7.10.2020).

Ipsen, Jörn. 2020. „Notstandsverfassung und Corona-Virus. Rückblick und Ausblick“. Recht und Politik 56 (2): 118-132.

Jones, Kate. 2020. „We're creating landscapes suited to the animals that transmit disease to us", Interview mit der Royal Society of Biology, 8.7.2020. https://thebiologist.rsb.org.uk/biologist/158-biologist/features/2404-there-were-at-leastthree-papers-in-2019-that-said-coronaviruses-might-be-a-real-problem-in-southchina-3 (abgerufen am 30.8.2020).

Koselleck, Reinhart. 1973. Kritik und Krise. Eine Studie zur Pathogenese der bürgerlichen Welt. Frankfurt/M.: Suhrkamp.

Krökel, Ulrich. 2020. „Eine Versuchung für Autoritäre“. Zeit Online, 23.3.2020. https://www.zeit.de/politik/ausland/2020-03/coronavirus-osteuropa-ukraine-ungarn-polen-demokratie-pandemie-folgen (abgerufen am 8.10.2020).

Lemke, Matthias. 2019. „Die Empirie von Ausnahmezuständen. Grenzziehungen zwischen Demokratierettung und Normalisierung“. Kriminologisches Journal 51 (4): 290-299.

Macron, Emmanuel. 2020. „Nous sommes en guerre': le verbatim du discours d'Emmanuel Macron“. Le Monde, 16.3.2020. https://www.lemonde.fr/ politique/article/2020/03/16/nous-sommes-en-guerre-retrouvez-le-discours-de-macron-pour-lutter-contre-le-coronavirus 6033314 823448.html (abgerufen am 30.8.2020).

Mason, Rowena. 2020. „Boris Johnson reacted too slowly to Covid-19, says former scientific adviser". The Guardian, 15.4.2020. https://www.theguardian.com/pol- 
itics/2020/apr/15/boris-johnson-reacted-too-slowly-to-covid-19-says-ex-scientific-adviser (abgerufen am 30.8.2020).

Menke, Christoph. 2004. Spiegelungen der Gleichheit. Politische Philosophie nach Adorno und Derrida. Frankfurt/M.: Suhrkamp.

Meyer-Ladewig, Jens, Martin Nettesheim und Stefan von Raumer, Hrsg. 2017. EMRK Europäische Menschenrechtskonvention. Handkommentar. Baden-Baden: Nomos.

Möllers, Christoph. 2020a. „Parlamentarische Selbstentmächtigung im Zeichen des Virus“. Verfassungsblog, 26.3.2020. https://verfassungsblog.de/parlamentarische-selbstentmaechtigung-im-zeichen-des-virus (abgerufen am 30.8.2020).

Möllers, Christoph. 2020b. Freiheitsgrade. Elemente einer liberalen politischen Mechanik, Berlin: Suhrkamp.

Nancy, Jean-Luc. 2020. „A Much Too Human Virus“. European Journal of Psychoanalysis. https://www.journal-psychoanalysis.eu/a-much-human-virus (abgerufen am 30.8.2020).

Northoff, Erwin. 2020. „Ländern droht wegen Covid ein Ernährungsnotstand“. Welternährung. Fachjournal der Welthungerhilfe, Juni 2020. https://www.welthungerhilfe.de/welternaehrung/rubriken/krisen-humanitaere-hilfe/bringt-die-pandemie-auch-eine-ernaehrungskrise (abgerufen am 30.8.2020).

Office of the United Nations High Commissioner for Human Rights (OHCHR). März 2018. Report on the impact of the state of emergency on human rights in Turkey.

Price-Haywood, Eboni G., Jeffrey Burton, Daniel Fort und Leonardo Seoane. 2020. „Hospitalization and Mortality among Black Patients and White Patients with Covid-19“. The New England Journal of Medicine 382 (26): 2534-2543.

Quammen, David. „We Made the Coronavirus Epidemic“. The New York Times, 28.1.2020. https://www.nytimes.com/2020/01/28/opinion/coronavirus-china. html (abgerufen am 30.8.2020).

Rixen, Stephan. 2020. „Gesundheitsschutz in der Coronavirus-Krise - Die (Neu-) Regelungen des Infektionsschutzgesetzes“, Neue Juristische Wochenschrift 73: 1097-1103.

Rosendorff, Kathrin. 2020. „Corona-Demo: 500 Menschen bei Querdenken-Protest ,Trauriger Tag für Frankfurt““. Frankfurter Rundschau, 17.8.2020. https://www. fr.de/frankfurt/frankfurt-500-menschen-bei-querdenken-demo-90024397.html (abgerufen am 30.8.2020).

Sallard, Erwan, José Halloy, Didier Casane, Jacques van Helden und Étienne Decroly. 2020. „Retrouver les origines du SARS-CoV-2 dans les phylogénies de coronavirus“. Med Sci (Paris) 36 (8-9): 783-796.

Sayeh, Antoinette, und Ralph Chami. 2020. „Lifelines in Danger“. IMF Finance \& Development Magazine 57 (2): 16-19.

Scherrer, Lucien. 2020. „Diese schrecklichen Bilder - wie ein junger Italiener unsere Sicht auf das Coronavirus verändert hat". Neue Zürcher Zeitung, 30.5.2020. ht- 
tps://www.nzz.ch/feuilleton/corona-krise-das-bild-das-um-die-welt-gegangenist-ld.1558320 (abgerufen am 2.10.2020).

Schmitt, Carl. 2009. Politische Theologie. Vier Kapitel zur Lehre von der Souveränität. Berlin: Duncker \& Humblot.

Schmitt, Carl. 2010. Verfassungslehre. Berlin: Duncker \& Humblot.

Schmitt, Felix. 2020. „Die Verfassungswidrigkeit der landesweiten Ausgangsverbote", Neue Juristische Wochenschrift 73: 1626-1631.

Schröder, Axel. 2020. „Der Boom der Corona-Verschwörungstheorien“. Deutschlandfunk, 16.4.2020. https://www.deutschlandfunk.de/falschmeldungen-zu-covid-19-der-boom-der-corona.724.de.html?dram:article id=474810 (abgerufen am 4.10.2020).

Schulz, Sarah. 2019. Die freiheitliche demokratische Grundordnung. Ergebnis und Folgen eines historisch-politischen Prozesses. Weilerswist: Velbrück Wissenschaft.

Schweizer Fernsehen SRF. 2020. „Coronavirus: Bedrohung der Demokratie?“, in $1 O$ vor $1 O$ vom 24.3.2020. https://www.srf.ch/play/tv/10vor10/video/coronavirus-bedrohung-der-demokratie?id=dc71d1f9-83f1-4878-9d33-c6d5foefc 833 (abgerufen am 8.10.2020).

Schweizer Radio SRF. 2020. „Die Rohingya-Flüchtlinge waren komplett eingesperrt“, in Echo der Zeit vom 24.8.2020. https://www.srf.ch/play/radio/echo-der-zeit/ audio/die-rohingya-fluechtlinge-waren-komplett-eingesperrt?id=a02a0553d2ob-4ca4-a069-738gfbac65c8 (abgerufen am 8.10.2020).

Schwering, Markus. 2020. „Jürgen Habermas über Corona: ,So viel Wissen über unser Nichtwissen gab es noch nie““. Frankfurter Rundschau, 15.4.2020. https:// www.fr.de/kultur/gesellschaft/juergen-habermas-coronavirus-krise-covid19-interview-13642491.html (abgerufen am 1.10.2020).

Skinner, Quentin. 2008. Freiheit und Pflicht. Thomas Hobbes' politische Theorie. Frankfurt/M.: Suhrkamp.

Tollefson, Jeff. 2020. „Why deforestation and extinctions make pandemics more likely“. Nature online, 7.8.2020. https://www.nature.com/articles/d41586-02002341-1 (abgerufen am 30.8.2020).

United Nations. Juni 2020. Policy Brief: The Impact of COVID-19 on Food Security and Nutrition.

Wihl, Tim. 2017. „Der Ausnahmezustand in Frankreich. Zwischen Legalität und Rechtsstaatsdefizit“. Kritische Justiz 50 (1): 68-80.

Wurzel, Steffen. 2020. „WHO-Schmusekurs mit China. Viel Lob und wenig Wachsamkeit“. Tagesschau, 15.4.2020. https://www.tagesschau.de/ausland/coronavirus-who-china-101.html (abgerufen am 4.10.2020).

Žižek, Slavoj. 2020a. Pandemic! COVID-19 Shakes the World. New York und London: OR Books.

Žižek, Slavoj. 2020b. „Der Mensch wird nicht mehr derselbe gewesen sein: Das ist die Lektion, die das Coronavirus für uns bereithält". Neue Zürcher Zeitung, 13.3.2020. https://www.nzz.ch/feuilleton/coronavirus-der-mensch-wird-niemehr-derselbe-gewesen-sein-ld.1546253 (abgerufen am 30.8.2020). 